\title{
Study of Oriented Organization of Fixed Assets Investment Project Management Mode
}

\author{
Yongli Lou \\ Electronic Product Reliability and Environmental Testing Institute, Guangzhou 510610, China \\ gzwslyl@163.com
}

Keywords: Fixed asset investment; project; oriented organization.

\begin{abstract}
Investment in fixed assets is the unit normal operation, the completion of the basic conditions and material basis for various tasks. With investment projects continue to expand in size, number and geographical, of the tradition of innovation project organization model posed new challenges. This paper describes the project organization structure type, the factors affecting the selection of the organizational structure were analyzed, and the main characteristics of multi Proposed Project-oriented organizational structure, the number of more and more cases of large-scale optimization under fixed assets investment of more than project management model for a useful discussion.
\end{abstract}

\section{Introduction}

In recent years, with the rapid development of China's economy, enterprises appear in all aspects of the new investment in fixed assets, the same amount of time in the project implementation, the phenomenon of acceptance multiple projects simultaneously at different stages of increasingly common. How to improve the organization and management of the project under the new situation, a new project management issues facing enterprises.

\section{The project organization structure type}

Project organization is the organization established for the completion of the project, is the core of project management. Traditional project organization structure types are: Engi- neering Command type, tissue function, project organization and matrix tissue type. Specific features are as follows:

(1) Engineering Command type: Since 1964, China's large-scale projects mainly taken this form, is still widely used, the advantages of the project implementation process betw- een appearing with each other to solve the problem with a quick decision-making, efficien- cy high characteristic; drawback is that the form is the way the administration, many aspects of the law is not in line with the market economy, modern project management employed in the project headquarters project organization, either in form or content than the earlier project headquarters unit type has been greatly improved.

(2) The functions of organization type: the pyramid structure, executives at the top of the pyramid, middle and bottom managers distributed along the top and bottom of the to-wer. Various departments involved in the project sent to the participants of the department heads report to the inter-departmental coordination among department heads, no full-time project manager. This approach is based on the organizational structure of the functions of the most common items organized.

(3) Project organization type: In this form of organization, each project like a miniature company that operates the project team members from different departments, the resources required to complete each project is fully allocated to this project, specifically for the project services.

(4) a matrix organization type: modern large-scale projects in the widely used form of organization, it is a combination of functional tissue type and tissue type of project, the lat-eral longitudinal strengths and advantages of project organization type functional tissue effe-ctively together. A matrix type organization by the vertical combination of departments and different levels of the project team 
made a matrix, the combination of centralization and decentralization, thereby strengthening the collaboration between the various departments wi- th between projects.

The first three are mostly single project organization type, tissue type two-dimensional matrix structure, vertical specialization implemented by departments, responsible for the ma-nagement of the business; multi-project to project basis laterally divided, the project can be implemented in parallel at the same time, it is the arrangement of one type of tissue.

\section{The factors that influence organizational structure selection}

Choose what kind of organizational structure and can not be generalized, select the appropriate type of organizational structure by a variety of factors.

Project Selection own characteristics affect organizational structure. Each project is uni-que, one-off projects with clear objectives and certain constraints, while the type of organiz-ational structure, specific responsibilities, staffing due to the project nature, size, quantity, etc. vary, Project attributes of different nature is not the same unit, the same unit also diff-erent projects have different characteristics. Select the appropriate organizational structure ba-sed on characteristics of the project is very important.

Balancing items and the impact of the parent organization. Direct establish full-time pr-ofessional project team could harm other organizational activities, the impact of the parent organization and the project team disharmony, rely on it to complete the project will adver-sely affect the parent organization. Therefore, we need to consider making authority, resour-ce allocation, project results can be merging with the parent mainstream business.

Factors that affect the organization of cultural integration. Organizational culture and project management have a strong interaction relationship is mutually beneficial to the pro-motion, the mutual damage than good. Organizational culture is a further extension and de-velopment of corporate culture, good corporate culture, organizational culture is a necessary factor in the smooth progress of the project management.

But the right project organization structure is not always either or choice, the structure of different types of organizations in many cases mixing during the project management implementation, mixing different organizational structure may have greater flexibility.

\section{The project-oriented organization structure}

(1) project-oriented organization

Multi-project management in resource coordination, intersectoral collaboration and other issues than the single project management has many complexities. As a matrix organization multi-project organization structure type one, although can be implemented in parallel proj-ects, but when the project reaches a certain amount, the matrix of each management divide and rule lead to coordination problems difficult to solve, the functions of the project under the dual leadership in multi-project management situation so that members of the organiza-tion in a dilemma; at the same time, the project manager in charge of the overall perform-ance of the situation, it is difficult to obtain tissue matrix due rights. Therefore, the traditional organizational structure model can not adapt to the evolving requirements of project management.

Project-oriented organization is to implement a long-term project management organiza- tion, with a broad project management capabilities is an important structure type multi-pro-ject management. Domestic and foreign scholars on the project-oriented organization active- exploration, some scholars have defined as "a temporary project to production functions as a management center of the organization."

(2) the main features of the project-oriented organization

Project-oriented organizations use "project-based management" as the organization's strate-gic management approach, both for the daily operations and set of functions, but also carry out various project management activities temporary team, with the ability to integrated management, enabling 
organizations structure more flexible, project members have strong le-arning ability and capability of unity and cooperation, and the project, program and portfol- io work mode as a core organization, with strong projects, the ability to program and pro-ject portfolio management. Most project-oriented organization with projects as a project management office authorities allocation of resources, but the most important is the organizational culture of professional management and teamwork, organizational structure became the basic unit. These features make it a better form of organization under the multi-project management situation.

\section{Application-oriented organization in fixed assets investment in Project Management}

Fixed asset investment is an important economic activity of enterprises of the construc-tion and purchase of fixed assets. Project program after examination and approval system project proposal stage, feasibility study stage, the preliminary design phase, construction de- sign phase, construction preparation and implementation phase, the final acceptance stage and so on, the same unit have multiple projects simultaneously and separately for each inv-estment, progress, quality management of the project has become a common phenomenon, and still exists in the project management process, overstaffing, low productivity phenomen-on, although after a long period of reform has improved, but if you want to form a ration-al and efficient Multi-project management model is still long way to go. The following project-oriented organization as an important way of multi-project management, put forward the views of the project application oriented organization and management of investment in fixed assets, mainly in the following areas:

To maintain the stability of the unit level. Departments of enterprises and institutions of daily management agencies, is unity of the human resources division of management decisions, the relevant business sector is demand and consumer investment activities around the development needs of the target unit to carry out normal economic activities. To meet the business development needs for the purpose of resource allocation functions can be ba-sed to sector-specific implementation of the project management functions as the leading, st-eady development of enterprises and institutions, multi-project management is the basis and guarantee. Stability project results in favor of maintaining the parent organization of mutu-al integration needs.

A number of projects at different stages in the proposal stage, feasibility study phase to concrete implementation of project management functions principally responsible for the main focal point, technology, planning, marketing and other departments, the relevant busi- ness units responsible for human coordination support staff, it is a prerequisite for the sm-ooth progress of the project. The stability of the unit is a multi-level project can successfully enter basic project and implementation phase.

the relative stability of the project hierarchy. Knowledge-intensive enterprises, human resources project management, including project managers, technicians, procurement officers and other management personnel are relatively fixed, all from inside the unit, the relative fixity of personnel, management personnel and the number of units for less, or part of those involved in the labor-intensive temporary employment, at the same time, disposable items, temporary and uncertainties determine the characteristics needed temporary organization pro-ject officers to the unit led the integration of resources and a reasonable allocation of land. Enterprises and institutions to achieve two separate management of labor resources, the es-tablishment of the relative immobility and temporary. Maintaining relative stability of corpo-rate culture mastered the project organizational culture, organizational culture and innovation on the other hand the project is conducive to the promotion of enterprise culture.

The purpose of the project is much more concrete in the preliminary design stage, construction design phase, construction phase of implementation, the final acceptance phase in a unit relative to the fixed professionals as the main focal point to coordinate other managers for a specific person, or to other managers, respectively, as coordinator of the main focal points for the relative stability of the project hierarchy in favor of the integration of resources and configuration across multiple projects 
and project and between the units, and to develop a culture of innovation as a guide, the smooth progress of the project and strong strong foundation and protection.

Project-oriented management. The daily management of the project management depart-ments of enterprises and institutions, to establish a relatively stable project-oriented project management team. Multiple projects in various stages of implementation, project-oriented or-ganization and management in unit level as the basis, relying on the stability of two separ-ate projects, so flattened and efficient organizational structure, give full play to the manage-ment staff enthusiasm, creativity and initiative, implementation of the project management model, the smooth progress of the implementation of more projects. Project oriented organi-zation model shown in Fig. 1.

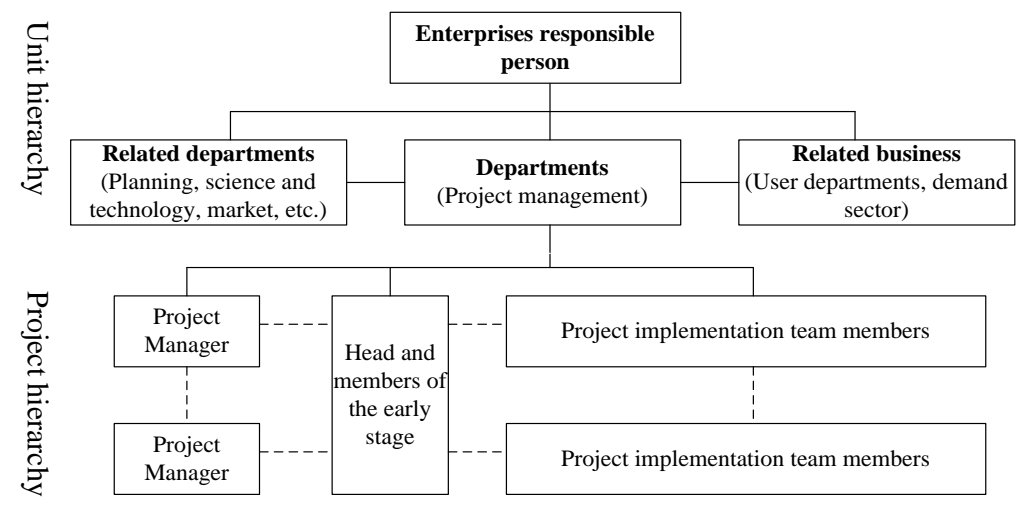

Fig. 1 Project oriented organi-zation model

\section{Conclusion}

Oriented organization applies to fixed-asset investment in multi-project management, tiered hierarchical management, improve project management level of enterprises and institutions to achieve effective allocation of resources to establish a project management departments rely on team-based project management the project-oriented organization and management model. Discussion oriented organization FAI multi-project management, project management innovation for our development needs have important reference value

\section{References}

[1] Ronggui Ding, Yanan Sun, Guanzhu Lv. Research organization mechanism project-oriented enterprises. Shandong University 2008 (6).

[2] Yuan Long, Sheng Chang. New development trend of process-oriented organization [J]. Enterprise Economy. 5(2001)110-111.

[3] Anbang Qin. On a project-oriented innovation-oriented society and organization-building programs [J]. China Science and Technology Forum. 5 (2008)46-47.

[4] Yiqun Xing, Xinyi Zheng. A new multi-project management - process-oriented organizational structure Mode [J]. Soft Science. 4 (2003) 42-43.

[5] Xiangnan $\mathrm{Lu}$, Xiangsong Zhu. On the project-oriented organization structure design. Economic and Management Research. 4(2004)77-78.

[6] Anbang Qin. Yuwu Yang, Yuanhong Liao, Lei Zhai. Oriented organizations and social research projects and innovative knowledge-based economy for the country. Science and Management. 4 (2006) 71-73. 